\title{
Single-Chamber versus Dual-Chamber Pacing for High-Grade Atrioventricular Block
}

\author{
William D. Toff, M.D., A. John Camm, M.D., and J. Douglas Skehan, M.B., B.S., \\ for the United Kingdom Pacing and Cardiovascular Events (UKPACE) \\ Trial Investigators*
}

\begin{abstract}
BACK GROUND

In the treatment of atrioventricular block, dual-chamber cardiac pacing is thought to confer a clinical benefit as compared with single-chamber ventricular pacing, but the supporting evidence is mainly from retrospective studies. Uncertainty persists regarding the true benefits of dual-chamber pacing, particularly in the elderly, in whom it is used less often than in younger patients.
\end{abstract}

\section{METHODS}

In a multicenter, randomized, parallel-group trial, 2021 patients 70 years of age or older who were undergoing their first pacemaker implant for high-grade atrioventricular block were randomly assigned to receive a single-chamber ventricular pacemaker (1009 patients) or a dual-chamber pacemaker (1012 patients). In the singlechamber group, patients were randomly assigned to receive either fixed-rate pacing (504 patients) or rate-adaptive pacing (505 patients). The primary outcome was death from all causes. Secondary outcomes included atrial fibrillation, heart failure, and a composite of stroke, transient ischemic attack, or other thromboembolism.

RESULTS

The median follow-up period was 4.6 years for mortality and 3 years for other cardiovascular events. The mean annual mortality rate was 7.2 percent in the single-chamber group and 7.4 percent in the dual-chamber group (hazard ratio, 0.96; 95 percent confidence interval, 0.83 to 1.11). We found no significant differences between the group with single-chamber pacing and that with dual-chamber pacing in the rates of atrial fibrillation, heart failure, or a composite of stroke, transient ischemic attack, or other thromboembolism.

\section{CONCLUSIONS}

In elderly patients with high-grade atrioventricular block, the pacing mode does not influence the rate of death from all causes during the first five years or the incidence of cardiovascular events during the first three years after implantation of a pacemaker.
From the Department of Cardiovascular Sciences, University of Leicester (W.D.T.), and the Department of Cardiology, University Hospitals of Leicester NHS Trust, Glenfield Hospital (W.D.T., J.D.S.), Leicester, United Kingdom; and the Division of Cardiac and Vascular Sciences, St George's University of London, London (A.J.C.). Address reprint requests to Dr. Toff at the Department of Cardiovascular Sciences, University of Leicester, Clinical Sciences Wing, Glenfield Hospital, Groby Rd., Leicester LE3 9QP, United Kingdom, or at w.toff@le.ac.uk.

*Other participating investigators are listed in the Appendix.

N EnglJ Med 2005;353:145-55.

Copyright $\odot 2005$ Massachusetts Medical Society. 
ARDIAC PACING IS THE ESTABLISHED treatment for high-grade atrioventricular block, but the appropriate pacing mode remains the subject of debate. ${ }^{1}$ Single-chamber ventricular pacing prevents bradycardia and death from ventricular standstill, but dual-chamber pacing better emulates normal cardiac physiology by restoring atrioventricular synchrony and matching the ventricular pacing rate to the sinus rate. As a result, dual-chamber pacing, as compared with single-chamber ventricular pacing, improves hemodynamic function, ${ }^{2-4}$ but the clinical benefit is uncertain.

Nonrandomized studies suggest that dualchamber pacing is associated with a lower incidence of atrial fibrillation, stroke, and heart failure than is single-chamber pacing. ${ }^{5}$ There is also evidence of improved survival, but the data are confounded by selection bias, because of the preferential use of dual-chamber pacing in younger patients with fewer coexisting illnesses. ${ }^{6}$ Some current guidelines recommend dual-chamber pacing unless atrial fibrillation is present, ${ }^{7}$ but the limitations of the supporting data have led to questions about the guidelines $^{8}$ and the apparent underuse of dual-chamber pacing, particularly in the elderly. ${ }^{9,10}$

The United Kingdom Pacing and Cardiovascular Events (UKPACE) trial compared the clinical benefits of single-chamber ventricular pacing and dual-chamber pacing in elderly patients with atrioventricular block. ${ }^{10}$

\section{METHODS}

The UKPACE trial was a randomized, parallel-group trial conducted in 46 centers in the United Kingdom, representing a wide range of experience among centers and operators. The trial was approved by the North West Multi-Centre Research Ethics Committee and the local research ethics committee for each center. All patients provided written informed consent.

\section{PATIENT SELECTION}

Patients were recruited from August 22, 1995, to September 24, 1999. All new pacemaker implantations were registered, and trial eligibility was recorded. Eligible patients were 70 years of age or older and scheduled for their first pacemaker implantations for high-grade (i.e., second-degree or complete) atrioventricular block. Exclusion criteria included chronic established atrial fibrillation,
New York Heart Association (NYHA) class IV heart failure, advanced cognitive dysfunction, total immobility, and advanced cancer (life expectancy of less than one year). Patients with persistent atrial fibrillation of less than three months' duration were eligible if they had undergone cardioversion and had normal sinus rhythm at enrollment.

\section{DATA COLLECTION, RANDOMIZATION, IMPLANTATION, AND PROGRAMMING}

Baseline demographic and clinical characteristics of the patients were recorded by physicians, nurses, or cardiac technicians. Patients were randomly assigned, up to 24 hours before the scheduled implantation, to receive either a fixed-rate or rate-adaptive single-chamber ventricular pacing system or a dual-chamber system (with or without sensor-modulated rate adaptation). Within the single-chamber group, assignment to fixed-rate or rateadaptive pacing was randomly determined. Randomization was performed with the use of a 24-hour automated telephone-based system, linked to a computer at the data center, with a dynamic balancing algorithm that stratified patients by center and age ( $<80$ years or $\geq 80$ years). Implantation was performed according to the operator's usual practice.

The use of sensor-based rate adaptation in the dual-chamber group and the programming of variables other than mode were determined by the investigator. Suggested settings for dual-chamber pacemakers were an atrioventricular delay of 150 msec, rate-adaptive atrioventricular shortening to $75 \mathrm{msec}$, and lower and upper rate limits of 60 beats per minute and 125 beats per minute, respectively. For rate-adaptive single-chamber pacemakers, the suggested lower and upper rate limits were 70 beats per minute and 125 beats per minute, respectively. For fixed-rate single-chamber pacemakers, a rate of 70 beats per minute was suggested. The operators and patients were not blinded to the type of pacing system used or the programming of the system.

\section{END POINT AND OUTCOMES}

The primary end point was death from all causes. Prespecified cardiovascular events included atrial fibrillation (defined as an episode, with or without symptoms, lasting 15 minutes or more and verified by electrocardiography), new or significantly worsening heart failure, a composite of stroke, transient ischemic attack, or other thromboembolism, revision of the pacing system, new-onset angina 
or newly diagnosed ischemic heart disease, and myocardial infarction. Crossover, in the event of suspected intolerance of the pacing mode, was at the discretion of the investigator.

Patients were followed for a minimum of 3 years, with scheduled visits at 1, 4, 10,16, and 36 months, at which the pacemaker function was assessed and outcome events were recorded. Patients were given a diary in which the details of any medical contacts between their follow-up visits were to be recorded. The identity of enrolled patients was given to the U.K. Office for National Statistics, which provided automatic notification of registered deaths. Mortality data were censored on September 24, 2002. Data for other cardiovascular events were censored at the actual or intended date of the 36month visit. If the visit was missed, outcome data were sought through a review of clinical records or through contact with the patient's family doctor. Deaths and specified cardiovascular events were adjudicated and classified by an independent committee on end points and events, with members unaware of the pacing modes. Deaths were classified as due to cardiovascular or noncardiovascular causes and treated as the result of cardiovascular causes if attributed to old age or if the cause was unclear. Safety was monitored by an independent data-monitoring committee.

\section{STATISTICAL ANALYSIS}

The database was maintained and analyzed by an independent data-management group (Nottingham Clinical Research Group, Nottingham, United Kingdom). The trial was designed to have a power of at least 90 percent to detect a 25 percent reduction in the primary end point, with a target recruitment of 2000 patients. This assumed an annual mortality rate of 8 percent in the single-chamber group, with allowance for a 6 percent crossover from single-chamber to dual-chamber pacing. More deaths were reported than anticipated, giving the study 95 percent power to detect a 25 percent reduction in mortality.

Differences in the proportion of ventricular beats that were paced were compared with the use of the Wilcoxon rank-sum test. Cumulative-event rates were calculated according to the Kaplan-Meier method, ${ }^{11}$ and differences between the groups were assessed with the use of the Cox proportionalhazards model, ${ }^{12}$ with adjustment for the baseline covariates of age ( $\leq 80$ years vs. $>80$ years), sex, and NYHA class (I or II vs. III or IV). Relative risk was calculated after adjustment for age, sex, and NYHA class at baseline and expressed as hazard ratios with 95 percent confidence intervals. The primary analysis was the comparison of single-chamber and dualchamber pacing. A prespecified secondary analysis involved the separate comparisons of fixed-rate and rate-adaptive single-chamber pacing with dualchamber pacing. The impact of baseline covariates on the hazard ratio for the primary end point was assessed with the use of the log-rank test. ${ }^{13}$ The incidence of procedural and predischarge complications in the two groups was compared with the use of the chi-square test. All statistical tests were two-tailed. Analysis was performed on the basis of the intention-to-treat principle.

The study was designed by Drs. Toff, Skehan, and Camm and David de Bono in collaboration with the trial steering committee and other participating investigators (see the Appendix) and funded by the Medical Research Council of the United Kingdom. Pacemakers were purchased according to normal practice, but in centers that had previously implanted less than 50 percent dual-chamber pacing systems, additional hardware costs were met by a subsidy from pacemaker manufacturers and suppliers under the terms of an agreement with the International Association of Prosthesis Manufacturers. No pacemaker manufacturer or supplier had any involvement in the study design, data collection, analysis of results, or writing of the manuscript. The manuscript was written by the principal investigators and the first draft reviewed by the trial steering committee and other participating investigators.

\section{RESULTS}

\section{SCREENING}

During the recruitment period, 16,375 patients received a first pacemaker implantation at the participating centers. Of these, 5308 ( 32.4 percent) had high-grade atrioventricular block and were 70 years of age or more. Exclusion criteria were documented in 945 patients, leaving 4363 eligible for the study, of whom 1972 (45.2 percent) were enrolled. The remaining patients were excluded because the patient declined to participate (13.2 percent), because the physician declined (15.0 percent), or for other or unstated reasons (26.6 percent). Forty-nine patients who were enrolled were not included in the registry either because they did not receive a pacemaker or because registry data were missing for the relevant period. 


\begin{tabular}{|c|c|c|c|}
\hline Characteristic & $\begin{array}{c}\text { Single-Chamber Fixed- } \\
\text { Rate Pacing Group } \\
(\mathrm{N}=504)\end{array}$ & $\begin{array}{c}\text { Single-Chamber Rate- } \\
\text { Adaptive Pacing Group } \\
\text { (N=505) }\end{array}$ & $\begin{array}{c}\text { Dual-Chamber } \\
\text { Pacing Group } \\
(\mathrm{N}=1012)\end{array}$ \\
\hline Age (yr) & $79.8 \pm 6.0$ & $80.1 \pm 6.1$ & $79.9 \pm 6.1$ \\
\hline Male sex (\%) & 56.0 & 57.4 & 57.2 \\
\hline White race $(\%) \dagger$ & 95.2 & 95.2 & 96.5 \\
\hline \multicolumn{4}{|l|}{ New York Heart Association functional class (\%) } \\
\hline 1 & 26.4 & 27.5 & 30.1 \\
\hline II & 43.4 & 45.0 & 42.1 \\
\hline III & 25.6 & 23.0 & 24.0 \\
\hline IV & 1.0 & 2.2 & 0.9 \\
\hline Unknown & 3.6 & 2.4 & 2.9 \\
\hline Cardiothoracic ratio on chest radiograph (\%) & $55.7 \pm 9.8$ & $55.9 \pm 10.6$ & $55.6 \pm 11.8$ \\
\hline \multicolumn{4}{|l|}{$\begin{array}{l}\text { Primary electrocardiographic indication } \\
\text { for implantation (\%) }\end{array}$} \\
\hline Second-degree atrioventricular block & 26.2 & 25.1 & 26.6 \\
\hline Complete atrioventricular block & 73.2 & 74.3 & 72.9 \\
\hline Other or unknown & 0.6 & 0.6 & 0.5 \\
\hline \multicolumn{4}{|l|}{ Presenting bradycardia (\%) } \\
\hline Intermittent & 38.7 & 38.2 & 38.0 \\
\hline Constant & 60.7 & 61.2 & 61.6 \\
\hline Unknown & 0.6 & 0.6 & 0.4 \\
\hline \multicolumn{4}{|l|}{ Symptoms of bradycardia (\%) } \\
\hline Symptomatic & 79.2 & 81.4 & 84.7 \\
\hline Asymptomatic & 20.2 & 18.0 & 15.0 \\
\hline Unknown & 0.6 & 0.6 & 0.3 \\
\hline \multicolumn{4}{|l|}{ Medical history (\%) } \\
\hline Hypertension & 30.8 & 32.1 & 35.7 \\
\hline Diabetes & 9.9 & 11.5 & 13.5 \\
\hline Angina & 20.8 & 22.0 & 22.7 \\
\hline Prior myocardial infarction & 15.5 & 15.4 & 12.8 \\
\hline Prior heart failure & 15.1 & 16.0 & 16.0 \\
\hline Cardiac surgery & 3.2 & 4.0 & 5.3 \\
\hline Percutaneous coronary angioplasty & 0.6 & 0.8 & 0.5 \\
\hline Paroxysmal atrial fibrillation & 3.6 & 3.8 & 4.6 \\
\hline Other arrhythmia & 10.9 & 10.7 & 11.5 \\
\hline Stroke & 6.3 & 5.9 & 5.4 \\
\hline Prior transient ischemic attack & 4.6 & 7.5 & 3.9 \\
\hline
\end{tabular}

\section{TREATMENT ASSIGN MENT}

Of 2021 patients enrolled, 1009 were randomly assigned to receive single-chamber pacing and 1012 to receive dual-chamber pacing. In the single-chamber group, 504 were assigned to fixed-rate pacing and 505 to rate-adaptive pacing. Of those assigned to single-chamber pacing, 99.4 percent received a single-chamber system, 0.2 percent received a dual-chamber system, and 0.4 percent received no pacemaker. Of those assigned to dual-chamber pacing, 95.8 percent received a dual-chamber system, 3.6 percent received a single-chamber system, and 0.6 percent received no pacemaker.

At hospital discharge, the programmed mode 


\begin{tabular}{|c|c|c|c|}
\hline Table 1. (Continued.) & & & \\
\hline Characteristic & $\begin{array}{l}\text { Single-Chamber Fixed- } \\
\text { Rate Pacing Group } \\
(\mathrm{N}=504)\end{array}$ & $\begin{array}{l}\text { Single-Chamber Rate- } \\
\text { Adaptive Pacing Group } \\
\text { (N=505) }\end{array}$ & $\begin{array}{l}\text { Dual-Chamber } \\
\text { Pacing Group } \\
\text { (N=1012) }\end{array}$ \\
\hline \multicolumn{4}{|l|}{ Medication at randomization (\%) } \\
\hline Aspirin & 38.7 & 39.4 & 42.2 \\
\hline Warfarin or other anticoagulant & 5.6 & 5.9 & 5.6 \\
\hline Angiotensin-converting-enzyme inhibitor & 18.7 & 18.4 & 17.8 \\
\hline Diuretic & 44.6 & 47.7 & 49.1 \\
\hline Nitrate or other vasodilator & 17.7 & 18.2 & 18.8 \\
\hline Beta-blocker & 8.5 & 5.5 & 6.9 \\
\hline Calcium-channel blocker & 13.1 & 14.5 & 17.2 \\
\hline Digoxin & 1.4 & 1.4 & 1.9 \\
\hline Other antiarrhythmic agent & 2.4 & 2.0 & 2.0 \\
\hline Lipid-lowering agent & 2.6 & 3.8 & 2.9 \\
\hline Oral hypoglycemic agent & 4.0 & 6.3 & 6.7 \\
\hline Insulin & 2.0 & 2.2 & 2.3 \\
\hline Nonsteroidal antiinflammatory drug & 9.1 & 6.5 & 7.0 \\
\hline Antidepressant & 3.2 & 4.4 & 4.4 \\
\hline
\end{tabular}

$*$ Plus-minus values are means \pm SD. Because of rounding, not all percentages total 100 .

$\uparrow$ Race was determined by the investigators.

of pacing was documented for 99 percent of the patients enrolled. At least 98.9 percent of those assigned to single-chamber pacing were being paced in a single-chamber mode, and at least 95.2 percent of those assigned to dual-chamber pacing were being paced in a dual-chamber mode. At the final follow-up or at the study end point, at least 96.9 percent of the patients assigned to singlechamber pacing were receiving this type of pacing, and at least 91.7 percent of those assigned to dualchamber pacing were being paced in a dual-chamber mode. At the conclusion of the study, 3.1 percent of patients had crossed over from single-chamber to dual-chamber pacing, primarily because of suspected intolerance of the pacing mode.

The extent of ventricular pacing, as assessed from the pacemaker's memory at one month, was recorded for 65 percent of all patients. The median percentage of ventricular beats that were paced was 94 percent in the fixed-rate single-chamber group, 93 percent in the rate-adaptive single-chamber group, and 99 percent in the dual-chamber group. The difference in ventricular paced beats between the single-chamber group and the dual-chamber group was statistically significant $(\mathrm{P}<0.001)$, but the difference between fixed-rate and rate-adaptive single-chamber pacing was not $(\mathrm{P}=0.85)$.

\section{BASELINE CHARACTERISTICS}

The treatment groups were well balanced with regard to baseline demographic and clinical characteristics (Table 1). The mean age of the patients was 79.9 years; 57 percent were male. The indication for pacing was second-degree atrioventricular block in 26.1 percent of patients and complete atrioventricular block in 73.3 percent. Bradycardia was judged as constant in 61.3 percent of patients and intermittent in 38.2 percent. Eightythree percent of patients were symptomatic.

\section{OUTCOME EVENTS}

The median follow-up period was 4.6 years for death and 3 years for other cardiovascular events. No patients were lost to follow-up with respect to the primary end point. Figure 1 shows KaplanMeier estimates of the cumulative risk of death from all causes and from cardiovascular causes in the two treatment groups, and Figure 2 shows es- 


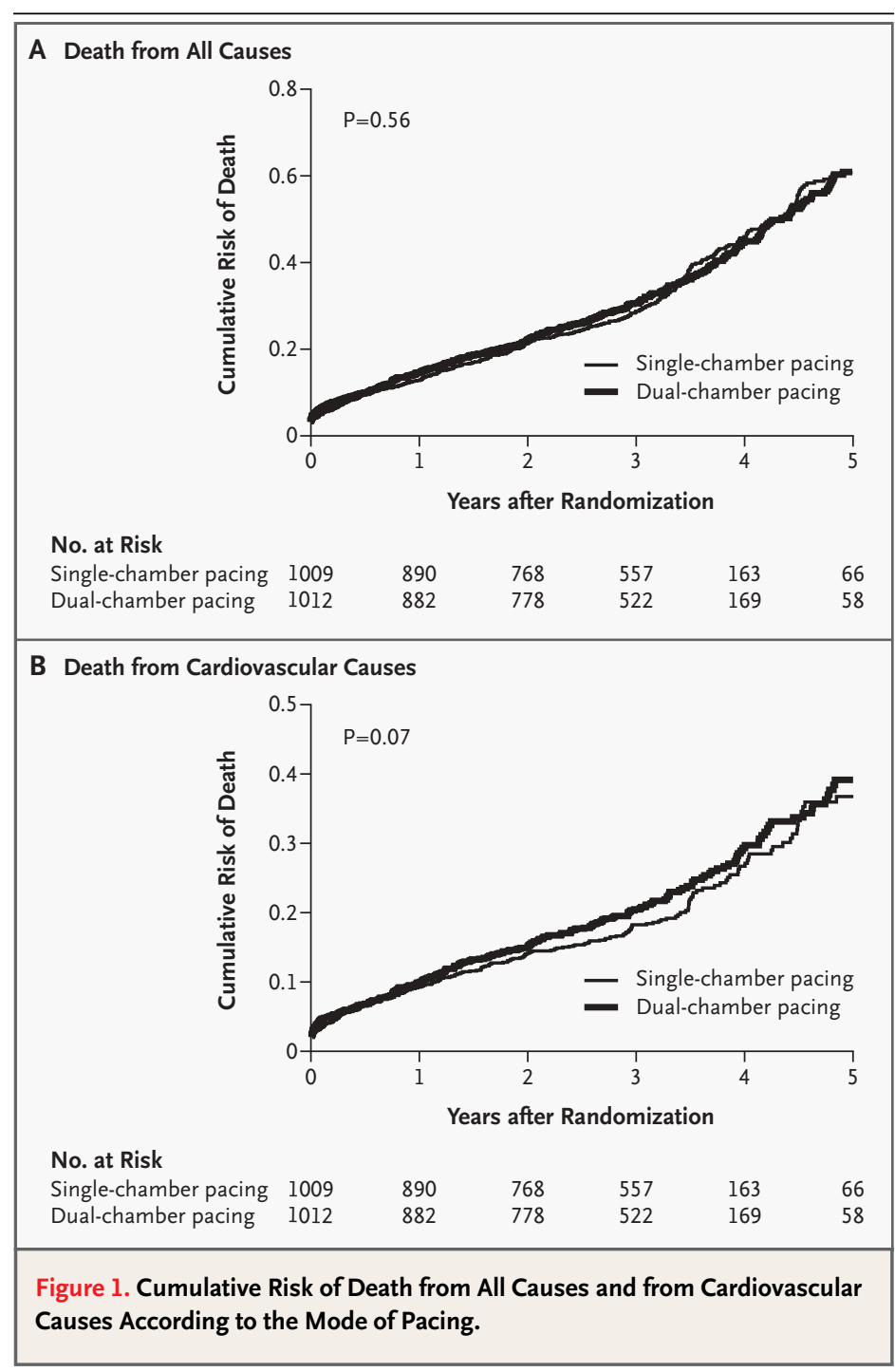

timates for the risk of the specified cardiovascular events. Table 2 shows event rates and hazard ratios for death from all causes, death from cardiovascular causes, and specified cardiovascular events for the primary comparison of single-chamber pacing with dual-chamber pacing; also shown are the event rates and hazard ratios for the separate comparison of fixed-rate and rate-adaptive single-chamber pacing with dual-chamber pacing.

\section{Mortality}

The mean annual rate of death from all causes during the first five years after pacemaker implantation was 7.2 percent in the single-chamber group and 7.4 percent in the dual-chamber group $(\mathrm{P}=0.56)$. The mean annual rate of death due to cardiovascular causes was 3.9 percent in the single-chamber group and 4.5 percent in the dualchamber group $(\mathrm{P}=0.07)$.

\section{Atrial Fibrillation}

There was a higher incidence of atrial fibrillation in the dual-chamber group during the first 18 months after pacemaker implantation but no significant difference in the mean annual event rates at 3 years, which were 3.0 percent in the singlechamber group and 2.8 percent in the dual-chamber group $(\mathrm{P}=0.74)$.

\section{Stroke, Transient Ischemic Attack, or Thromboembolism}

For the combined outcome of stroke, transient ischemic attack, or thromboembolism, the mean annual event rate was 2.1 percent in the single-chamber group and 1.7 percent in the dual-chamber group $(\mathrm{P}=0.20)$. There was a significantly higher event rate with fixed-rate single-chamber pacing (2.5 percent per year) than with dual-chamber pacing $(\mathrm{P}=0.04)$, but the event rate in the rate-adaptive single-chamber group (1.7 percent per year) was the same as that in the dual-chamber group $(\mathrm{P}=0.93)$.

\section{Heart Failure, Angina, and Myocardial Infarction}

There was no significant difference in the mean annual event rate for heart failure, which was 3.2 percent in the single-chamber group and 3.3 percent in the dual-chamber group ( $\mathrm{P}=0.80$ ). Similarly, there was no significant difference between the single-chamber and dual-chamber groups in event rates for new-onset angina or ischemic heart disease or for myocardial infarction.

\section{SUBGROUP ANALYSIS}

The subgroup analysis showed that the presence or absence of selected baseline characteristics did not affect the influence of the pacing mode on the primary end point (Fig. 3).

\section{COMPLICATIONS}

Procedural complications were more common in the dual-chamber group than in the single-chamber group (7.8 percent vs. 3.5 percent, $\mathrm{P}<0.001)$, as were other complications before discharge (10.4 percent vs. 6.1 percent, $\mathrm{P}<0.001)$. The need for therapeutic intervention was also more frequent in the dual-chamber group (8.8 percent vs. 5.6 percent, $\mathrm{P}=0.005$ ), as were complications requiring 
repeated operation before discharge $(4.2$ percent vs. 2.5 percent, $\mathrm{P}=0.04)$. The differences in complication rates were principally due to problems with the placement or stability of atrial leads.

\section{I SCUSSION}

The key finding from this randomized trial was that in elderly patients with high-grade atrioventricular block, dual-chamber pacing provided no survival advantage over single-chamber pacing. This result contrasts with the findings of nonrandomized studies that suggested there was improved survival with dual-chamber pacing, which probably reflected selection bias. ${ }^{6,14}$

Our trial focused on atrioventricular block in the elderly, but the absence of a survival advantage for dual-chamber pacing is consistent with the results of other trials that included younger patients and those with sinus-node disease. In the Pacemaker Selection in the Elderly (PASE) study, 407 patients 65 years of age or older with sinus-node disease or atrioventricular block were randomly assigned to receive single-chamber ventricular pacing or dual-chamber pacing. ${ }^{15}$ The study was not powered to assess mortality, but there was no significant difference in survival or clinical outcomes during the mean follow-up period of 18 months, although the crossover rate from ventricular to dual-chamber pacing was high (26 percent).

In the Canadian Trial of Physiologic Pacing (CTOPP), 2568 patients 18 years of age or older who had sinus-node disease or atrioventricular block were randomly assigned to physiologic (atrial or dual-chamber) pacing or single-chamber ventricular pacing. ${ }^{16}$ During the mean follow-up period of three years, there was no significant difference in the rate of death from all causes or in the primary end point of cardiovascular death or stroke. There was an 18 percent reduction in the relative risk of atrial fibrillation with dual-chamber pacing but no significant difference in the rate of hospitalization for heart failure or in the occurrence of stroke. Follow-up extended to a mean of 6.4 years showed a further reduction in the relative risk of atrial fibrillation (20.1 percent) but no other benefit from physiological pacing. ${ }^{17}$

The absence of a reduction in atrial fibrillation with dual-chamber pacing in the UKPACE trial contrasts with the findings of the CTOPP trial. This difference may reflect the older age of our patients, in whom any propensity toward atrial fibrillation

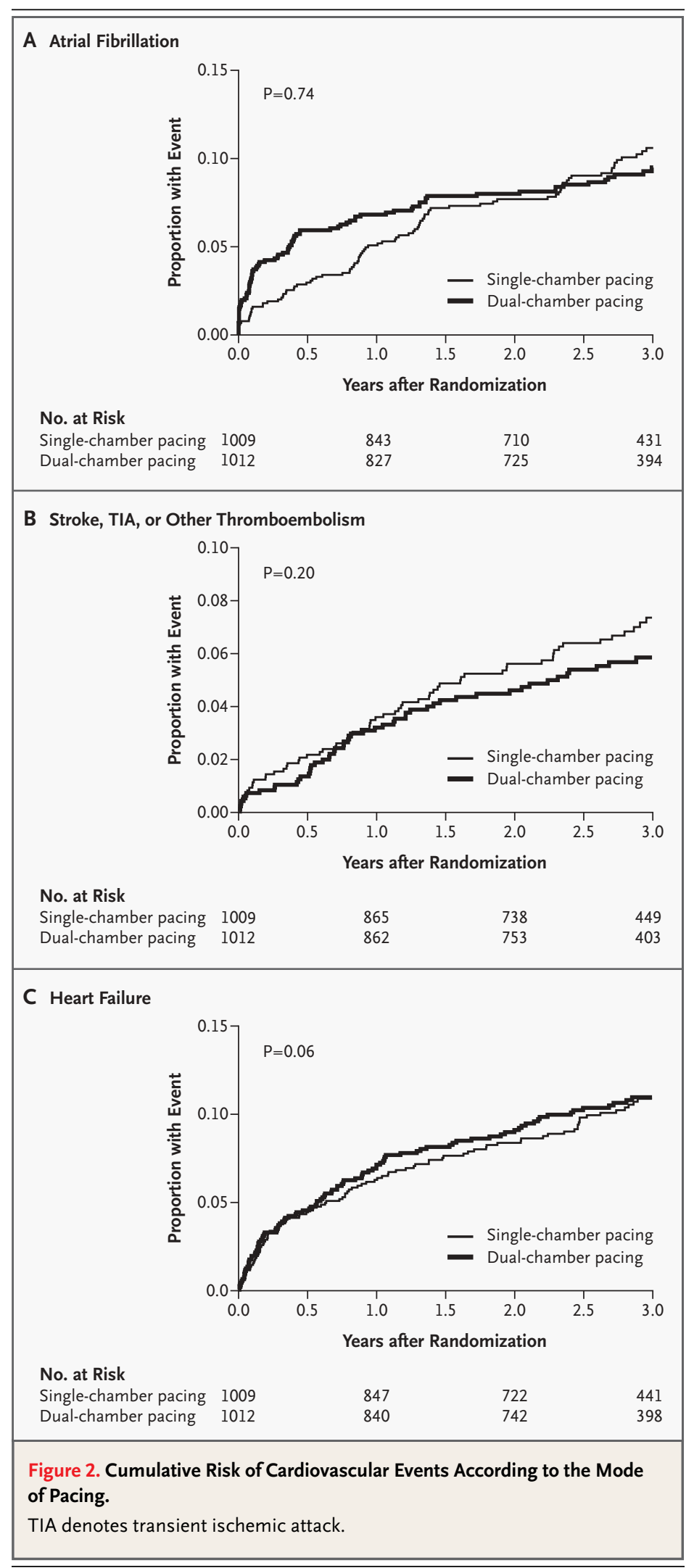




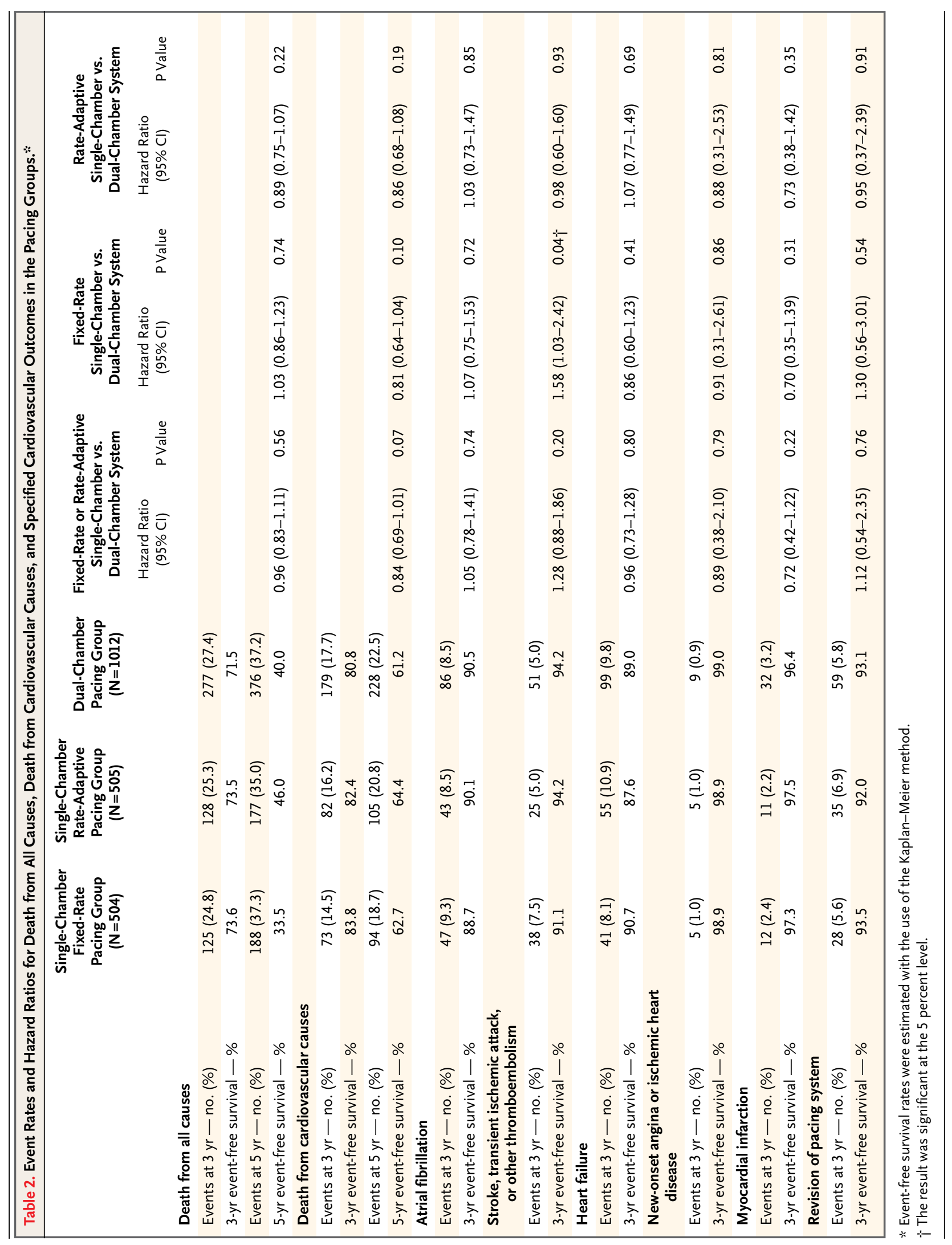




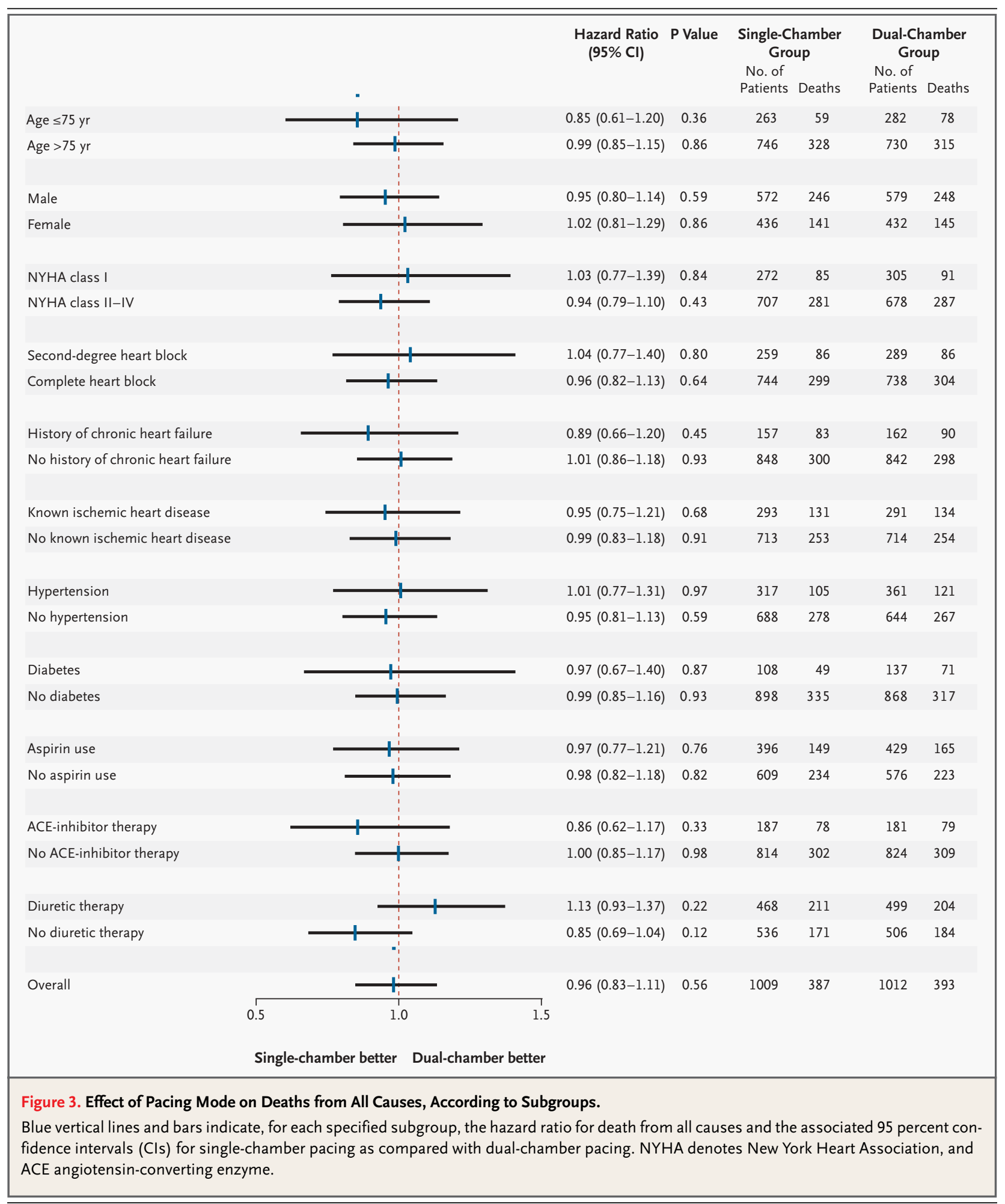


might be less readily influenced by pacing mode. Although the CTOPP trial included patients with sinus-node disease, the reduction in atrial fibrillation with physiologic pacing was also seen in the subgroup with atrioventricular block. ${ }^{18}$ In the CTOPP trial, the difference in the incidence of atrial fibrillation emerged only at two years. It is possible that with longer follow-up of our patients, a difference might also emerge among them.

An interesting feature in our study was the increased early incidence of atrial fibrillation in the dual-chamber group. It is possible that the atrial lead may be arrhythmogenic in the early months after implantation. Alternatively, the capacity of dual-chamber pacemakers to detect high-rate atrial episodes might have led to an earlier recognition of atrial fibrillation. This capability might also increase the overall likelihood that atrial fibrillation will be detected with these systems, potentially masking a benefit of dual-chamber pacing; however, the diagnostic requirement of an electrocardiographically verified episode lasting 15 minutes or longer would be expected to attenuate the effect of such a bias.

The finding that there was a higher rate of stroke, transient ischemic attack, or thromboembolism with fixed-rate ventricular pacing is intriguing. Conceivably, the lower heart rates associated with fixed-rate pacing might promote atrial stasis, but the finding could be due to the play of chance amid multiple comparisons and should be interpreted with caution. The observation may, however, favor the use of a rate-adaptive system if a single-chamber ventricular pacemaker is used.

Our results, supported by the PASE and CTOPP trials, suggest that the clinical benefits associated with dual-chamber pacing for atrioventricular block have been overestimated. It is perhaps counterintuitive that the hemodynamic advantages of atrioventricular synchrony do not result in greater clinical benefit. One explanation for this may be that intraventricular and interventricular dyssynchrony resulting from stimulation at the right ventricular apex might counteract the benefit of atrioventricular synchrony. ${ }^{19,20}$ This effect might be accentuated by the higher proportion of paced ventricular beats in the dual-chamber group. It is possible that alternative strategies, such as biventricular or septal pacing, might improve hemodynamic function and clinical outcomes. This hypothesis requires testing in clinical trials.
The low crossover rate (3.1 percent) from single-chamber to dual-chamber pacing in our study was similar to that in the CTOPP trial (2.7 percent), suggesting that single-chamber pacing is well tolerated. The higher crossover rate in the PASE study (26 percent), in which randomization to mode of pacing was made by software programming rather than by assignment of hardware, may reflect variation in the incidence of pacemaker syndrome but also highlights the subjective element in the diagnosis of this syndrome.

The choice of pacing mode for elderly patients with high-grade atrioventricular block should be made on an individual basis. Over three years, dualchamber pacing is unlikely to influence mortality or the incidence of cardiovascular events, and single-chamber ventricular pacing should be regarded as an acceptable mode. The occasional need to upgrade to dual-chamber systems because of pacing-mode intolerance must be weighed against the increased risk of complications with dual-chamber implants. In elderly patients, factors other than the mode of pacing are more likely to determine the clinical outcome.

In elderly patients with high-grade atrioventricular block, the mode of pacing has no significant influence on the rate of death from all causes in the first five years after pacemaker implantation. Fixed-rate single-chamber ventricular pacing is associated with an increased risk of stroke, transient ischemic attack, or thromboembolism, but the pacing mode does not otherwise influence the incidence of cardiovascular events in the first three years after pacemaker implantation.

Supported by a grant from the Medical Research Council of the United Kingdom (G9403190). Dr. Camm holds a chair funded by the British Heart Foundation. In centers that had previously implanted less than 50 percent dual-chamber pacing systems, additional hardware costs were met by a subsidy from the following pacemaker manufacturers and suppliers under an agreement with the International Association of Prosthesis Manufacturers: Biotronik, Cardiocare, CPI-Guidant, ELA Medical, Intermedics, Medtronic, St. Jude Medical, Sorin Biomedica, Telectronics, and Vitatron.

International Standard Randomized Controlled Trial No. 37445539.

Dr. Toff reports having received lecture fees from St. Jude Medical. Dr. Skehan reports having received consulting fees and having served on the advisory board for Medtronic. Dr. Camm reports having received consulting fees and having served on advisory boards for Guidant, St. Jude Medical, and Vitatron and having received lecture fees from St. Jude Medical and Vitatron.

This article is dedicated to the patients who participated in the trial and to the memory of Prof. David de Bono, coprincipal investigator, who died on April 29, 1999.

We are indebted to the many technical, medical, nursing, and clerical staff members who provided support at the participating centers. 
APPENDIX

The following institutions and investigators participated in the UKPACE trial (total numbers of patients recruited are indicated in parentheses): Glenfield Hospital, Leicester (343) - J.D. Skehan, W.D. Toff, J. Villanueva, J. Kovac, K. Percy, and G.H. Broomes; Freeman Hospital, Newcastle (170) — R.S. Bexton, S. Henderson, and J. Cronin; St George's Hospital, London (154) — A.J. Camm, E. Rowland, D.E. Ward, and S. Jones; Cardiothoracic Centre, Liverpool (139) — R.G. Charles, J. Morland-Duff, and S. Hughes; Queen Elizabeth Hospital, Birmingham (120) — M.D. Gammage, D. Jones, A. Barber, and Z. Harris; Derbyshire Royal Infirmary, Derby (79) - A. McCance and J.E. Penrice; Northern General Hospital, Sheffield (72) — R.J. Bowes and R. Ecob; Blackpool Victoria Hospital, Blackpool (71) — G.K. Goode and A. Delaney; Hull Royal Infirmary, Hull (68) — G.C. Kaye and T. Houghton; Treliske Hospital, Truro (64) - A.K.B. Slade and F. Westwood; University Hospital of Wales, Cardiff(60) - M.B. Buchalter and C. McCormack; John Radcliffe Hospital, Oxford (52) - O.J.M. Ormerod, K. Johnston, and Y. Bashir; UCH/Middlesex Hospitals, London (50) D. Holdright, R.H. Swanton, and M. Squirrell; Queen's Medical Centre, Nottingham (49) — R.G. Wilcox and S. Jones; Royal Devon and Exeter Hospital, Exeter (45) - J.W. Dean and S. Crowsley; Ninewells Hospital, Dundee (39) - T.H. Pringle and D. Jamieson; Wessex Cardiothoracic Centre, Southampton (39) - J.M. Morgan and R. Williams; Solihull Hospital, Solihull (39) — K. Priestley and P. Brennan; Wordsley Hospital, Stourbridge (35) - E.J. Flint, P. Forsey, and A. Drewnicki; Good Hope Hospital, Sutton Coldfield (30) - R.E.A. Smith and J. Tipping; Derriford Hospital, Plymouth (29) - C.J. Burrell and I. Lines; Southern General Hospital, Glasgow (26) - D. Murdoch and C. Vaughan; Ipswich Hospital, Ipswich (24) — R.M. Oliver and C.J. Woollard; St. Bartholomew's Hospital, London (24) - A.W. Nathan and J. Sibley; Papworth Hospital, Cambridge (23) — M.C. Petch and S. Newell; Western Infirmary, Glasgow (22) - J.D. McArthur and S. Starkey; Nottingham City Hospital, Nottingham (20) - A.J. Ahsan and J. Riley; County Hospital, Hereford (16) - J. Glancy and D. Thomas; Stobhill Hospital, Glasgow (14) - K.J. Hogg and Y. Brown; Stafford General Hospital, Stafford (12) - P.A. Woodmansey and M. Batthew; Royal Sussex County Hospital, Brighton (12) - S. O'Nunain and L. Bennett; Manor Hospital, Walsall (11) - A. Cunnington and C. Boden; New Cross Hospital, Wolverhampton (10) - J.W. Pidgeon and K. Nicholas; Glasgow Royal Infirmary, Glasgow (9) - S.M. Cobbe and C. Armour; Hairmyres Hospital, East Kilbride (7) - K. Oldroyd, B. Vallance, and J. Young; Glan Clywd Hospital, Bodelwyddan (6) - G.J. Green and N. Waterfield; Maelor Hospital, Wrexham (6) - R.P.W. Cowell and M.E. Antony; The General Infirmary, Leeds (5) - G.W. Reynolds and A. Nicholls; Royal Free Hospital, London (5) - J.G. Coghlan and W. Smith; St Mary's Hospital, London (4) — N.S. Peters and J. Varghese; Sandwell Hospital, West Bromwich (4) — P.J. Cadigan and A. Ridney; Wansbeck General Hospital, Ashington (4) — B. Thwaites and J. Cronin; Beaumont Hospital, Dublin (3) - T. Gumbrielle and J. Bedford; City Hospital, Birmingham (3) - T. Millane; Doncaster Royal Infirmary, Doncaster (3) - G.E. Payne and V. Hayward; Heartlands Hospital, Birmingham (1) - P. Ludman, J.M. Beattie, and S. Ramzan: Trial Steering Committee - S.M. Cobbe (chair), S.G. Ball, J.M. Bland, M.J. Buxton, and R. Sutton; Data Monitoring Committee - P. Sleight (chair), R.J.C. Hall, S.J. Pocock, and P.A. Poole-Wilson; End Points and Events Committee - M.C. Petch (chair), M.B. Buchalter, C.J. Burrell, J.C. Cowan, M.D. Gammage, R.T. Johnston, A.N. Sulke, and G.S. Venables; Data Management Center (Nottingham Clinical Research Group) - A.M. Skene (director), L. Brown, A. Charlesworth, M. Goulder, J. Sprague, and S. Stead.

\section{REFERENCES}

1. Gregoratos G, Cheitlin MD, Conill A, et al. ACC/AHA guidelines for implantation of cardiac pacemakers and antiarrhythmia devices: a report of the American College of Cardiology/American Heart Association Task Force on Practice Guidelines (Committee on Pacemaker Implantation). J Am Coll Cardiol 1998;31:1175-209.

2. Kruse I, Arnman K, Conradson TB, Rydén $\mathrm{L}$. A comparison of the acute and longterm hemodynamic effects of ventricular inhibited and atrial synchronous ventricular inhibited pacing. Circulation 1982;65:84655.

3. Boon NA, Frew AJ, Johnston JA, Cobbe SM. A comparison of symptoms and intraarterial ambulatory blood pressure during long term dual chamber atrioventricular synchronous (DDD) and ventricular demand (VVI) pacing. Br Heart J 1987;58:34-9.

4. Lau CP, Wong CK, Leung WH, Liu WX Superior cardiac hemodynamics of atrioventricular synchrony over rate responsive pacing at submaximal exercise: observations in activity sensing DDDR pacemakers. Pacing Clin Electrophysiol 1990;13:1832-7.

5. Tang CY, Kerr CR, Connolly SJ. Clinical trials of pacing mode selection. Cardiol Clin 2000;18:1-23.

6. Lamas GA, Pashos CL, Normand SLT, McNeil B. Permanent pacemaker selection and subsequent survival in elderly Medicare pacemaker recipients. Circulation 1995;91: 1063-9.

7. Clarke M, Sutton R, Ward D, et al. Recommendations for pacemaker prescription for symptomatic bradycardia: report of working party of the British Pacing and Electrophysiology Group. Br Heart J 1991; 66:185-91.

8. Petch MC. Who needs dual chamber pacing? BMJ 1993;307:215-6.

9. Payne GE, Skehan JD. Issues in cardiac pacing: can agism be justified? Br Heart J 1994;72:102-3.

10. ToffWD, Skehan JD, De Bono DP, Camm AJ. The United Kingdom Pacing and Cardiovascular Events (UKPACE) trial. Heart 1997;78:221-3.

11. Kaplan EL, Meier P. Nonparametric estimation from incomplete observations. J Am Stat Assoc 1958;53:457-81.

12. Cox DR. Regression models and lifetables. J R Stat Soc [B] 1972;34:187-220.

13. Peto R, Pike MC, Armitage P, et al. Design and analysis of randomized clinical trials requiring prolonged observation of each patient. II. Analysis and examples. $\mathrm{Br}$ Cancer 1977;35:1-39.

14. Jahangir A, Shen WK, Neubauer SA, et al. Relation between mode of pacing and long-term survival in the very elderly. J Am Coll Cardiol 1999;33:1208-16.

15. Lamas GA, Orav EJ, Stambler BS, et al.
Quality of life and clinical outcomes in elderly patients treated with ventricular pacing as compared with dual-chamber pacing. N Engl J Med 1998;338:1097-104.

16. Connolly SJ, Kerr CR, Gent M, et al. Effects of physiologic pacing versus ventricular pacing on the risk of stroke and death due to cardiovascular causes. $\mathrm{N}$ Engl J Med 2000;342:1385-91.

17. Kerr CR, Connolly SJ, Abdollah $\mathrm{H}$, et al. Canadian Trial of Physiological Pacing: effects of physiological pacing during longterm follow-up. Circulation 2004;109:35762.

18. Skanes AC, Krahn AD, Yee R, et al. Progression to chronic atrial fibrillation after pacing: The Canadian Trial of Physiologic Pacing. J Am Coll Cardiol 2001;38:167-72. 19. Wilkoff BL, Cook JR, Epstein AE, et al. Dual-chamber pacing or ventricular backup pacing in patients with an implantable defibrillator: the Dual Chamber and VVI Implantable Defibrillator (DAVID) Trial. JAMA 2002;288:3115-23.

20. Sweeney MO, Hellkamp AS, Ellenbogen $\mathrm{KA}$, et al. Adverse effect of ventricular pacing on heart failure and atrial fibrillation among patients with normal baseline QRS duration in a clinical trial of pacemaker therapy for sinus node dysfunction. Circulation 2003;107:2932-7.

Copyright (c) 2005 Massachusetts Medical Society. 